\title{
Comparative Characterisation of 3-D Hydroxyapatite Scaffolds Developed Via Replication of Synthetic Polymer Foams and Natural Marine Sponges
}

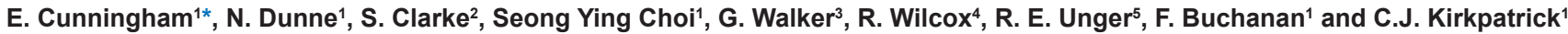 \\ ${ }^{1}$ School of Mechanical and Aerospace Engineering, Queen"s University Belfast, Ashby Institute, Belfast, BT9 5AH, UK \\ ${ }^{2}$ School of Biological Sciences, Queen"s University Belfast, Medical Biology Centre, Belfast, UK \\ ${ }^{3}$ School of Chemistry and Chemical Engineering, Queen"s University Belfast, David Keir Institute, Belfast, UK \\ ${ }^{4}$ School of Mechanical Engineering, University of Leeds, Leeds, UK \\ ${ }^{5}$ Institute of Pathology, University Medical Center, REPAIR Lab, Johannes Gutenberg University, Mainz, Langenbeckstr. 1, Mainz 55101, Germany
}

\begin{abstract}
The production of complex inorganic forms, based on naturally occurring scaffolds offers an exciting avenue for the construction of a new generation of ceramic-based bone substitute scaffolds. The following study reports an investigation into the architecture (porosity, pore size distribution, pore interconnectivity and permeability), mechanical properties and cytotoxic response of hydroxyapatite bone substitutes produced using synthetic polymer foam and natural marine sponge performs. Infiltration of polyurethane foam (60 pores/in2) using a high solid content $(80 \mathrm{wt} \%)$, low viscosity $(0.126 \mathrm{Pas})$ hydroxyapatite slurry yielded $84-91 \%$ porous replica scaffolds with pore sizes ranging from $50 \mu \mathrm{m}-1000 \mu \mathrm{m}$ (average pore size $577 \mu \mathrm{m}$ ), $99.99 \%$ pore interconnectivity and a permeability value of $46.4 \times 10-10 \mathrm{~m} 2$. Infiltration of the natural marine sponge, Spongia agaricina, yielded scaffolds with $56-$ $61 \%$ porosity, with $40 \%$ of pores between $0-50 \mu \mathrm{m}, 60 \%$ of pores between $50-500 \mu \mathrm{m}$ (average pore size $349 \mu \mathrm{m}$ ), $99.9 \%$ pore interconnectivity and a permeability value of $16.8 \times 10-10 \mathrm{~m} 2$. The average compressive strengths and compressive moduli of the natural polymer foam and marine sponge replicas were $2.46 \pm 1.43 \mathrm{MPa} / 0.099 \pm 0.014 \mathrm{GPa}$ and $8.4 \pm 0.83 \mathrm{MPa} / 0.16 \pm 0.016 \mathrm{GPa}$ respectively.
\end{abstract}

Cytotoxic response proved encouraging for the HA Spongia agaricina scaffolds; after 7 days in culture medium the scaffolds exhibited endothelial cells (HUVEC and HDMEC) and osteoblast (MG63) attachment, proliferation on the scaffold surface and penetration into the pores.

It is proposed that the use of Spongia agaricina as a precursor material allows for the reliable and repeatable production of ceramic-based 3-D tissue engineered scaffolds exhibiting the desired architectural and mechanical characteristics for use as a bone 3 scaffold material. Moreover, the Spongia agaricina scaffolds produced exhibit no adverse cytotoxic response.

\section{Introduction}

Given the well documented limitations of traditional bone repair (auto-, allo- or xeno-grafts) such as limited availability, donor site morbidity and risks of an adverse immune response, biomaterial researchers have a responsibility to develop alternatives that will enhance the functional capabilities of bone graft substitutes and eliminate the need for traditional grafting procedures [1]. In recent decades a variety of bone scaffold manufacturing techniques have been developed in an effort to address these limitations. Using ceramics, polymers or combinations of the two, solvent casting and particulate leaching [2], gas foaming [3], fibre meshes and fibre bonding [4], phase separation [2], melt moulding [5], emulsion freeze drying [6], solution casting [7], freeze drying [4], fused deposition modelling [8], rapid prototyping [9], membrane lamination [10], microsphere sintering [2], supercritical fluid technology [11] and various preform replication techniques [12-22] have all been employed to produce scaffolds with variable pore size, porosity and connectivity.

With the emergence of new techniques and materials hard tissue replacement has evolved from the use of biomaterials to repair or replace tissue into the development of controlled three-dimensional scaffolds to guide the proliferation and spread of cells in vitro and in vivo [23]. To achieve this, scaffolds should comply with the following criteria;

1. Scaffold architecture should mimic that of the tissue it aims to replace. The scaffold should (a) be highly porous; while Best et al recommend relatively high levels of 70-4 80\%, scaffolds with porosity between $45-90 \%$ have successfully induced bone growth [24] (b) have an appropriate pore size distribution; while the majority of pores should lie between 50 - 500 $\mu \mathrm{m}[21,25,26]$, according to Yang et al pores of $5-50 \mu \mathrm{m}$ are essential for neovascularisation and fibroblast and osteoblast in growth [27] and (c) have a high degree of interconnectivity between the pores; interconnectivity through openings of approximately $50 \mu \mathrm{m}$ is necessary to promote fluid circulation providing sufficient blood and cellular material to the core of the implant, enhancing bone deposition, nourishment of new bone and removal of waste products [28-30].

2. Obtaining the optimum pore architecture should not be achieved at the expense of structural integrity. A TE bone scaffold should have sufficient stability to maintain its architecture during in vitro culturing and handling throughout implantation. After implantation, the scaffold must possess similar mechanical

*Corresponding author: E. Cunningham, School of Mechanical \& Aerospace Engineering, Queen's University of Belfast, Ashby Building, Stranmillis Road, BT9 5AH, Belfast, UK.2, Tel: +442890 974236; Email Address: ecunningham07@qub. ac.uk

Received June 01, 2011; Accepted July 20, 2011; Published July 22, 2011

Citation: Cunningham E, Dunne N, Clarke S, Choi SY, Walker G, et al. (2011) Comparative Characterisation of 3-D Hydroxyapatite Scaffolds Developed Via Replication of Synthetic Polymer Foams and Natural Marine Sponges. J Tissue Sci Eng S1:001. doi:10.4172/2157-7552.S1-001

Copyright: @ 2011 Cunningham E, et al. This is an open-access article distributed under the terms of the Creative Commons Attribution License, which permits unrestricted use, distribution, and reproduction in any medium, provided the original author and source are credited. 
Citation: Cunningham E, Dunne N, Clarke S, Choi SY, Walker G, et al. (2011) Comparative Characterisation of 3-D Hydroxyapatite Scaffolds Developed Via Replication of Synthetic Polymer Foams and Natural Marine Sponges. J Tissue Sci Eng S1:001. doi:10.4172/2157-7552. S1-001

properties to the bone it has been designed to replace [31-33]. Once integration has occurred, the implanted scaffold should function in tandem with neighbouring healthy bone and assume a shared function, reducing the risk of rejection and failure.

3. The scaffold should be biocompatible i.e. it should have "the ability to perform with an appropriate host response in a specific application" [34]. The prerequisite for any potential biomaterial is successful vascularisation of the implanted TE scaffold [35].

4. Ideally the scaffold should resorb at a rate equal to the growth of new bone, allowing gradual transfer of load. 5 .The production technique utilized in this investigation, ceramic infiltration and replication of porous performs, has been reported by others with varying results as demonstrated in Table 1 [12-21]. According to the literature discussed, the larger pore size distribution attainable via the replication of commercial cellulose sponges (Table 1) should yield greater bone in growth than scaffolds produced via polymer foam replication. However, without quantification of pore interconnectivity, and, in all but Mastrogiacomo et al, any biological validation, it is difficult to accurately determine the performance of these scaffolds in vivo.

The authors have previously developed a 3-D hydroxyapatite (HA) scaffold production technique involving the replication of various porous preforms. Using an optimized high solid content $80 \mathrm{wt} \%(55.9$ vol\%) low viscosity HA slurry, polyurethane foams and marine sponges were infiltrated, squeezed to remove any excess ceramic and sintered to $1300^{\circ} \mathrm{C}$ to produce $3-\mathrm{D}$ porous scaffolds $[36,37]$. The aim of the present study is to fully validate these scaffolds in terms of their architectural, mechanical and biological properties.

\section{Materials and Methods}

\section{Hydroxyapatite slip and scaffold production}

Ceramic slip [36] and scaffold [37] production have been reported in previous publications. Briefly, predominantly spherically shaped particles of HA grade „S-BM” (Batch P260/S/BM/192; Plasma Biotal Ltd, UK) between $820 \mathrm{~nm}$ and $16.2 \mu \mathrm{m}$ were mixed with $2 \mathrm{wt} \%$ ammonium polyacrylate (Darvan 821A; R.T Vanderbilt Company, USA), an anionic polyelectrolyte.Through the addition of ever decreasing amounts of HA powder to a mixture of distilled water and Darvan $821 \mathrm{~A}$ over a period of $4 \mathrm{~d}, 50 \%$ of the total amount to be added on day $1,25 \%$ on day $2,15 \%$ on day 3 and the final $10 \%$ on day 4 , an $80 \mathrm{wt} \%$ (55.9 vol\%) solid loaded slip with a viscosity of $126 \mathrm{mPa}$ $\mathrm{s}$ was achieved. In order to fully homogenise the suspension it was continuously rotated on powered rollers for one week.

Scaffold production involves submerging the flexible polyurethane (PU) packaging foam $(\varnothing 10 \mathrm{~mm}, 10 \mathrm{~mm}$ height; 60 pores/in2; density, $30 \mathrm{~kg} / \mathrm{m} 3$ ) (Craftworld Ltd, UK) and the marine sponge ( $10 \times 10$ x 7-12mm), Spongia agaricina (Pure Sponge UK Ltd, UK), in the optimized 80wt $\%$ HA slurry followed by squeezing in a Collin W-100-T Two Roll Mill (LRS Planung and Technologie GMBH, Germany) with the rollers fixed at $3.5 \mathrm{~mm}$ apart. The specimens were then dried for $4 \mathrm{~h}$, turning every hour, followed by sintering in a box furnace (Elite Thermal Systems Ltd, UK) at $1300^{\circ} \mathrm{C}$. A ramp rate of 5 deg C min-1, a cooling rate of $3 \mathrm{deg} \mathrm{C}$ min-1, and a dwell time of $5 \mathrm{~h}$ were determined as the optimal sintering regime [38]. HA sintered using this regime exhibited a highly dense structure with minimal surface porosity phase change, the formation of microcracks, and the effects of coarsening (increased porosity around the grain boundaries compromising mechanical stability) have been successfully avoided [38].

\section{SEM/Image analysis}

Lucia Image Analysis software, version 4.82 (Laboratory Imaging, Czech Republic), was used to analyze the micrographs attained with a Jeol 6500 FEGSEM (Advanced MicroBeam, Inc). Pore dimensions were characterized by taking single measurements, in the case of spherical pores, and measurements of both the maximum and minimum for elliptical pores ( 5 measurements on 3 micrographs of 5 specimens). Additional relevant features were also measured such as micropores ( $<$ $20 \mu \mathrm{m})$ and pore clusters.

\section{Micro-CT analysis}

Pore size distribution and degree of interconnectivity were determined using a MicroCT80 (Scanco Medical, Switzerland), operating at $70 \mathrm{kV}$ and $114 \mu \mathrm{A}$ with a voxel size of $50 \mathrm{x} 50 \mathrm{x} 50 \mu \mathrm{m} 3$. The images were segmented using a constant threshold across the specimens and analyzed using the proprietary software (IPL, Scanco Medical, Switzerland). The pore diameter distribution was evaluated by using a distance transform method. The interconnectivity was calculated by component labelling and ranking the pore regions (of 200 voxels) and determining the percentage size of the largest component. An output format of serial TIFF images from the MicroCT80 also enabled 3D volumetric reconstruction to be performed using Mimics V10 (Materialise GMBH, Holland).

\section{Mercury Intrusion Porosimetry (MIP)}

Mercury Intrusion Porosimetry (MIP) was performed using a Quantachrome Poremaster 33 (Quantachrome Instruments, Florida, USA). After driving off any moisture by preheating the samples at $300^{\circ} \mathrm{C}$ for 4 hours, mercury $(\mathrm{Hg})$ was incrementally forced through the porous constructs using between $4-25 \mathrm{MPa}$ of pressure. Upon each incremental rise in pressure an equilibrium time of 10 seconds was implemented prior to taking readings of mean pore diameter, incremental and cumulative pore volume $(\mathrm{mL} / \mathrm{g})$ and pore area $(\mathrm{m} 2 / \mathrm{g})$

\section{Permeability}

The apparatus used to determine the permeability of the replica scaffolds was based on that used by Marshall et al. [39]. Cylindrical scaffolds $(\varnothing 0.01 \mathrm{~m}$, height $0.01 \mathrm{~m})$ wrapped in PTFE tape (leaving only the top and bottom exposed) and pre-infiltrated with water to remove any air bubbles (atmospheric pressure) were inserted into flexible PVC tubing $(\varnothing 0.01 \mathrm{~m})$. One end was then attached to a reservoir capable of generating various pressure gradients (via changes in water volume); the other was attached to a burette tube with a measurement bar. Using the method set out by Marshall et al. [39], the following steps were taken to determine the hydraulic permeability, $k$, through Spongia agaricina and PU foam replica scaffolds ( $\mathrm{n}=5$ for both). The rate of flow in the absence of specimens and through a series of PVC calibration plugs $(\varnothing 0.01 \mathrm{~m}$, height $0.012 \mathrm{~m})$ with between $1-5$ cylindrical pores of (Ø0.001-0.002m, height $0.012 \mathrm{~m}$ ) was analyzed to determine Darcy Velocity, VD (m/s), Equation 1.

$$
V_{D}=\frac{4\left(V_{2}-V_{1}\right)}{\pi D^{2}\left(t_{2}-t_{1}\right)}
$$

where V2 - V1 represents the change in water volume (in this investigation maintained at $10 \mathrm{ml}$ ), read off the graduated burette at times $\mathrm{t} 1$ (s) and $\mathrm{t} 2(\mathrm{~s})$ (where $\mathrm{t} 2$ - $\mathrm{t} 1$ is flow time measured for rising water level increase by V2-V1). D represents the scaffold diameter, in this case $0.01 \mathrm{~m}$. The average pressure gradient in $\mathrm{kPa} / \mathrm{m}, \nabla p$, is determined using Equation 2. 
Citation: Cunningham E, Dunne N, Clarke S, Choi SY, Walker G, et al. (2011) Comparative Characterisation of 3-D Hydroxyapatite Scaffolds Developed Via Replication of Synthetic Polymer Foams and Natural Marine Sponges. J Tissue Sci Eng S1:001. doi:10.4172/2157-7552. S1-001

Page 3 of 9

$$
\nabla p=\frac{\rho g \bar{h}}{d} * 10^{-3}
$$

Equation 2 where $\rho$ is the mass density of water at room temperature in $\mathrm{Kg} / \mathrm{m} 3$ (998), $g$ is the acceleration of gravity in $\mathrm{m} / \mathrm{s} 2$ (9.81), $d$ is the specimen thickness in $\mathrm{m}$, and is the average water head (in $\mathrm{m}$ ) for the time step $\nabla t=t 2-t 1$, determined using Equation 3.

$$
\bar{h}=\frac{h_{1}-h_{2}}{\operatorname{Ln}\left(h_{1} / h_{2}\right)}
$$

Equation 3 where $h 1$ and $h 2$ (in $\mathrm{m}$ ) are the water heads at times $t 1$ and $t 2$ respectively. Finally, the hydraulic permeability, $\mathrm{k}(\mathrm{m} 2)$ can be calculated using equation 4 Equation 4.

$$
k=\frac{\eta}{m} * 10^{-10}
$$

Where $\eta$ is the viscosity of water at room temperature in unit Pa.s $\left(0.96^{\star} 10-3\right)$ and $m$ is the slope of the $p$ vs. VD plot.

\section{Compositional Analysis - X-Ray Diffraction (XRD)}

It has been suggested that sintering $\mathrm{HA}$ at $1300^{\circ} \mathrm{C}$ can cause decomposition of the HA to anhydrous calcium phosphates such as tricalcium phosphate (TCP), which can lead to accelerated in vitro dissolution rates [40]. To ensure phase change had not occurred within the HA, XRD was performed using a Philips X" Pert PRO diffractometer (PANalytical UK, Cambridge, UK) and analyzed using Phillips X" Pert High Score Software. Samples of pre-sintered HA (3g) and crushed HA replicas of PU foam and 10 Spongia agaricina $(3 \mathrm{~g})$ were analyzed and each trace attained was compared to the stick pattern ICSD-2631 from the inorganic structural database (ICSD).

\section{Mechanical testing}

Mechanical testing allows comparison of the PU foam and Spongia agaricina replicas with each other, with 3 -D constructs manufactured using similar production techniques and with the properties of natural healthy bone.

Compression strength and modulus of the ceramic scaffolds was measured using a Lloyd Instruments EZ50. Advanced Materials Testing System (Lloyd Instruments Ltd, Fareham, UK). Scaffolds $(n=10)$ of both the PU foam and Spongia agaricina were loaded under compression to failure at $1 \mathrm{~mm}$ min- 1 using a $1 \mathrm{kN}$ load cell.

\section{Cytotoxic response after cell seeding}

Prior to cell seeding, the scaffolds were sterilized by immersion in $70 \%$ ethanol for $15-20$ mins followed by rising 2-3 times with sterile phosphate buffered saline (PBS). Ceramic scaffolds $(\mathrm{n}=12)$ of Spongia agaricina $(10 \times 10 \times 7-12 \mathrm{~mm})$ and $\mathrm{PU}$ foam $(\varnothing 10 \times 10 \mathrm{~mm})$ were placed into 24-well culture plates and pre-soaked in medium for $24 \mathrm{~h}$. Three cell types were used; primary human endothelial cells derived from umbilical vein (HUVEC), human dermal microvascular endothelial cells (HDMEC) and the osteoblast-like MG63 cell line. HUVECs were isolated from umbilical vein by collagenase digestion according to a published method [41] and cultured in M199 medium (SigmaAldrich, Germany) supplemented with $10 \%$ fetal calf serum (FCS; Life Technologies, Germany), 10\% FCS (PAA Laboratories, Germany), 100 $\mathrm{U} / 100 \mathrm{mg} / \mathrm{mL}$ Pen/Strep (Sigma-Aldrich, Germany), 2mM glutamax I (Life Technologies, Germany), $25 \mathrm{mg} / \mathrm{mL}$ sodium heparin 11 (SigmaAldrich, Germany) and $25 \mathrm{mg} / \mathrm{mL}$ endothelial cell growth supplement (ECGS, BD Biosciences, USA). HDMECs were isolated from juvenile foreskin as previously described [42] and were cultured in endothelial basal medium MV (PromoCell GmbH, Germany) supplemented with $15 \%$ fetal bovine serum (Invitrogen $\mathrm{GmbH}$, Darmstadt, Germany), 100 $\mathrm{U} / 100 \mathrm{mg} / \mathrm{ml}$ Penicillin/Streptomycin (Invitrogen), sodium heparin $(10 \mathrm{mg} / \mathrm{mL})$ and bFGF $(2.5 \mathrm{ng} / \mathrm{mL})$. MG63s were also cultured in M199 medium supplemented with $10 \% \mathrm{FCS}, 100 \mathrm{U} / \mathrm{mL}$ penicillin and 100 $\mathrm{mg} / \mathrm{mL}$ streptomycin.

1x105 cells were seeded onto each scaffold and the viability and morphology was assessed after 1, 3, 5 and $7 \mathrm{~d}$. Medium was replaced every 3 to $4 \mathrm{~d}$. At each time period scaffolds $(n=3)$ were placed in fresh medium and $2-3 \mu \mathrm{L}$ calcein-AM (Mobitec, Germany) was applied. In viable (living) cells calcein-AM was converted into a fluorescent dye, resulting in the distribution of green fluorescence throughout the cell cytoplasm [35]. Specimens were incubated for $30 \mathrm{mins}$ at $37^{\circ} \mathrm{C}$ and analyzed using a confocal laser scanning microscopy (CLSM) (Leica TCS NT, Wetzlar, Germany).

\section{Results}

\section{SEM/Image analysis of preform and scaffold architecture}

Having analyzed the micrographs in Figure 1 with Lucia Image Analysis software; the mean PU foam pore size (Figure 1b) was $520 \mu \mathrm{m}$ $(\mathrm{SD}=115)$. The polymer struts which form the walls of these pores were $120 \mu \mathrm{m}(\mathrm{SD}=40)$.

Pores within the PU foam replica scaffolds were a mean of $550 \mu \mathrm{m}$ $(\mathrm{SD}=50 \mu \mathrm{m})$ separated by $85 \mu \mathrm{m}(\mathrm{SD}=15 \mu \mathrm{m})$ struts (Figure $1 \mathrm{~h})$. There was evidence that the ceramic slip has pooled in regions, filling the pores of the preform, while in other areas the desired coating and replication of the struts has been achieved (Figure 1h). Figure 1(c-d and e-f) exhibit what Pronzato et al term as "inhalant" and "exhalent" surfaces of Spongia agaricina respectively, referred to as such due to directionality of water flow in the sponge"s natural habitat [43]. The intertwined fibrous struts, which are $16 \mu \mathrm{m}(\mathrm{SD}=8 \mu \mathrm{m})$ thick and $25 \mu \mathrm{m}$ $(\mathrm{SD}=5 \mu \mathrm{m})$ apart, form a mesh with regular macro pores of $470 \mu \mathrm{m}$ $(\mathrm{SD}=120 \mu \mathrm{m})$ on the inhalant surface, and regular clusters of 5-7 pores of $510 \mu \mathrm{m}(\mathrm{SD}=140 \mu \mathrm{m})$ on the exhalent surface. The macro pores on the inhalant surface are typically $275 \mu \mathrm{m}(\mathrm{SD}=75 \mu \mathrm{m})$ apart. The pore clusters on the exhalent surface are $600 \mu \mathrm{m}(\mathrm{SD}=200 \mu \mathrm{m})$ apart. Figure $1(\mathrm{i}-1)$ shows the surface features typically found on the Spongia agaricina replica scaffolds. While the majority of the space between fibrous struts was filled with the ceramic slip, macro pore patterns found on both the inhalant and exhalent surfaces of the natural preform were replicated in the ceramic scaffold. Pores on the replicated inhalant surface are $480 \mu \mathrm{m}(\mathrm{SD}=127 \mu \mathrm{m})$ and are $450 \mu \mathrm{m}(\mathrm{SD}=250 \mu \mathrm{m})$ apart.

Micro - computerised tomography: Approximately 35 and 91\% of pores, for the PU foam and Spongia agaricina replica scaffolds respectively, fall within $50-500 \mu \mathrm{m}$ (Figure 2), the range cited as optimum for bone ingrowth [27]. The average pore size was $577 \mu \mathrm{m}$ $(\mathrm{SD}=179 \mu \mathrm{m})$ and $349 \mu \mathrm{m}(\mathrm{SD}=109 \mu \mathrm{m})$ for PU foam and Spongia agaricina replicas respectively. Upon analysing regions of 200 cubic voxels within the Spongia agaricina and PU foam replica scaffolds it was determined that $99.92 \%$ and $99.99 \%$ of the volume of pores was interconnected and porosity was approximately 55\% and $89 \%$ respectively. Good agreement was found when the porosity of the scaffolds was determined using their 13 dimensions and the theoretical density of fully densified polycrystalline HA, i.e. $58.5 \pm 3 \%$ and 86.45 $\pm 6 \%$.

The mean strut size was $541 \mu \mathrm{m} \quad(\mathrm{SD}=304 \mu \mathrm{m})$ and $257 \mu \mathrm{m}$ $(\mathrm{SD}=95 \mu \mathrm{m})$ for the PU foam and Spongia agaricina replica scaffolds respectively. The mean strut size attained for the PU foam replicas may 
Citation: Cunningham E, Dunne N, Clarke S, Choi SY, Walker G, et al. (2011) Comparative Characterisation of 3-D Hydroxyapatite Scaffolds Developed Via Replication of Synthetic Polymer Foams and Natural Marine Sponges. J Tissue Sci Eng S1:001. doi:10.4172/2157-7552. S1-001
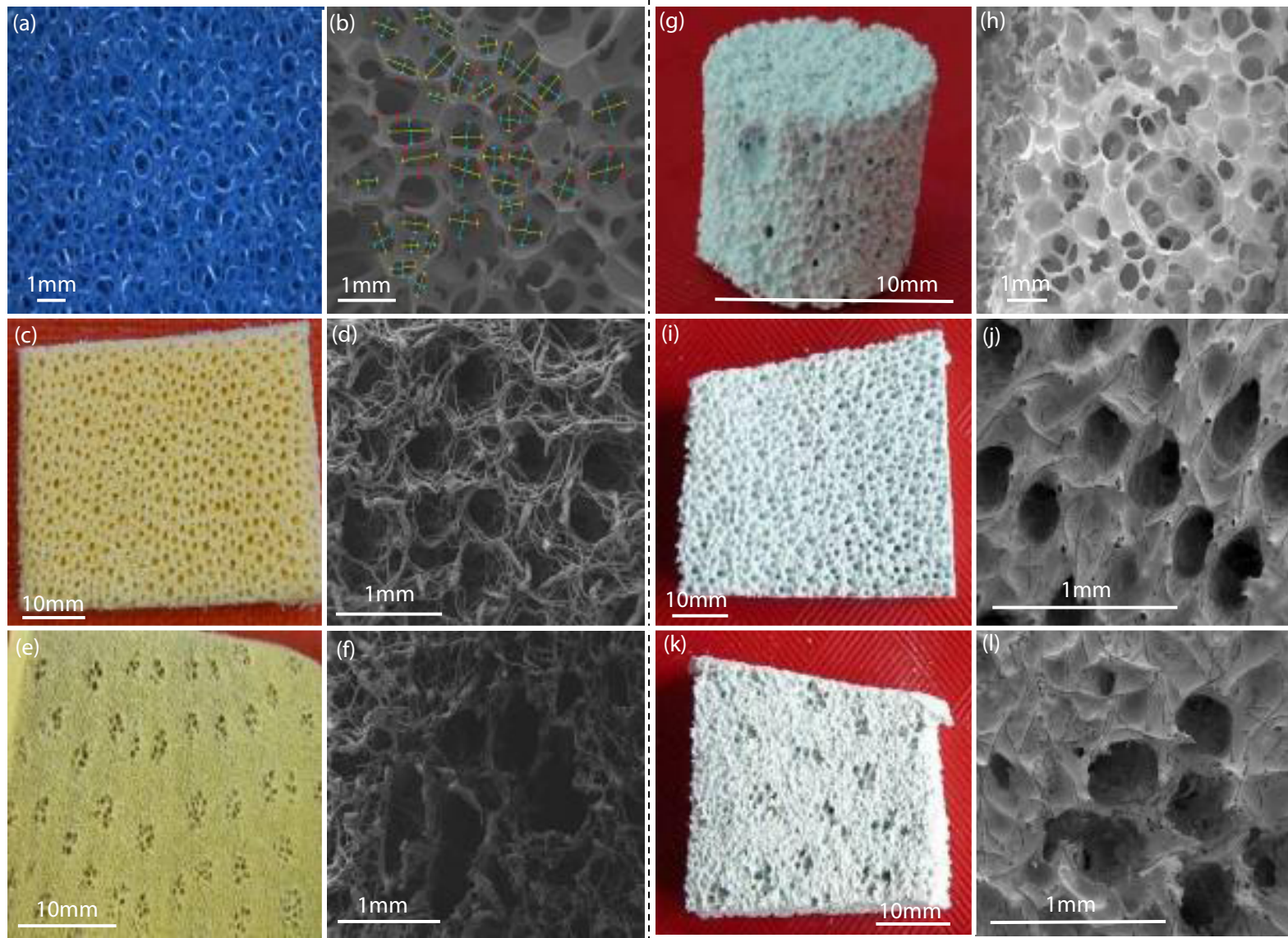

Figure 1: (a) Polyurethane foam (60PPI) (b) Typical image analysis showing strut thickness (red), maximum distance between struts (yellow) and minimum distance between struts (blue) (c) Inhalant surface of Spongia agaricina (d) Micrograph of inhalant surface (e) Exhalent surface of Spongia agaricina (f) Micrograph of typical pore cluster on exhalent surface of Spongia agaricina (g) Replicated PU foam (h) Porous and non-porous regions of replica PU foam (i) Replicated inhalant surface of Spongia agaricina (j) Micrograph of inhalant surface (k) Replicated exhalent surface of Spongia agaricina (I) Typical pore cluster on exhalent surface of Spongia agaricina.

be misleading, however, as there was evidence in the micrographs in Figure 3 (bottom line) that the ceramic slip has pooled in regions.

3-D reconstruction of $\mu$-CT slices using Mimics version 10 allowed qualitative assessment of the pore interconnectivity within the replica scaffolds, providing images of their internal architecture along $\mathrm{x}, \mathrm{y}$ and $\mathrm{z}$ axes (Figure 3 ).

\section{Mercury Intrusion Porosimetry (MIP)}

MIP data (Figure 4) indicated the Spongia agaricina replicas possessed a bimodal pore distribution with peaks occurring in both the micro $(<20 \mu \mathrm{m})$ and macro $(>50 \mu \mathrm{m})$ range. Spongia agaricina replicas comprise $48.2 \%$ of pores between $0-50 \mu \mathrm{m}$ and $51.8 \%$ between $50-500$ $\mu \mathrm{m}$. In contrast the pore size distribution within PU foam replicas is distinctly mono-modal with the majority of pores (70.2\%) ranged between 400 and $650 \mu \mathrm{m}$.

\section{Permeability}

Figure 5 exhibits average pressure gradient (determined using Equation 2) versus Darcy velocity (determined using Equation 1). Using Equation 4 the hydraulic permeability, $\mathrm{k}$, for the Spongia agaricina and PU foam replicas (equivalent to the gradient of their respective slopes) was determined to be $16.6 \times 10-10 \mathrm{~m} 2$ and $45.7 \times 10-10 \mathrm{~m} 2$ respectively.

\section{Compositional Analysis - X-Ray Diffraction (XRD) Analysis}

Peaks present in traces (b), (c) and (d), representing analysis of HA supplied by Plasma Biotal Ltd and crushed replicas of PU foam and Spongia agaricina marine sponge, correlate to the HA stick pattern (Trace a) attained from ICSD-2631 from the inorganic structural database (ICSD) (Figure 6).

\section{Mechanical properties}

After testing three batches of five specimens the mean compressive strength and compressive modulus of the Spongia agaricina replicas were $8.4 \pm 0.83 \mathrm{MPa}$ and $163.6 \pm 16.4 \mathrm{MPa}$ respectively. The compressive strength and compressive modulus of the PU foam replicas were $0.95 \pm 0.31 \mathrm{MPa}$ and $99 \pm 13.75 \mathrm{MPa}$ respectively. Figure 7 exhibits typical stress vs. strain curves for both the PU foam and Spongia agaricina replicas. Comparatively the mechanical performance of PU foam replicas, which completely disintegrated under stresses and strain rates of $<1 \mathrm{MPa}$ and $1-2 \%$ respectively, was considerably inferior to replicas of Spongia agaricina, for which fracture occurred at a stress of $10 \mathrm{MPa}$ and strain values $>10 \%$. Even under greater loading conditions Spongia agaricina replicas only partially fractured. 
Citation: Cunningham E, Dunne N, Clarke S, Choi SY, Walker G, et al. (2011) Comparative Characterisation of 3-D Hydroxyapatite Scaffolds Developed Via Replication of Synthetic Polymer Foams and Natural Marine Sponges. J Tissue Sci Eng S1:001. doi:10.4172/2157-7552. S1-001

Page 5 of 9

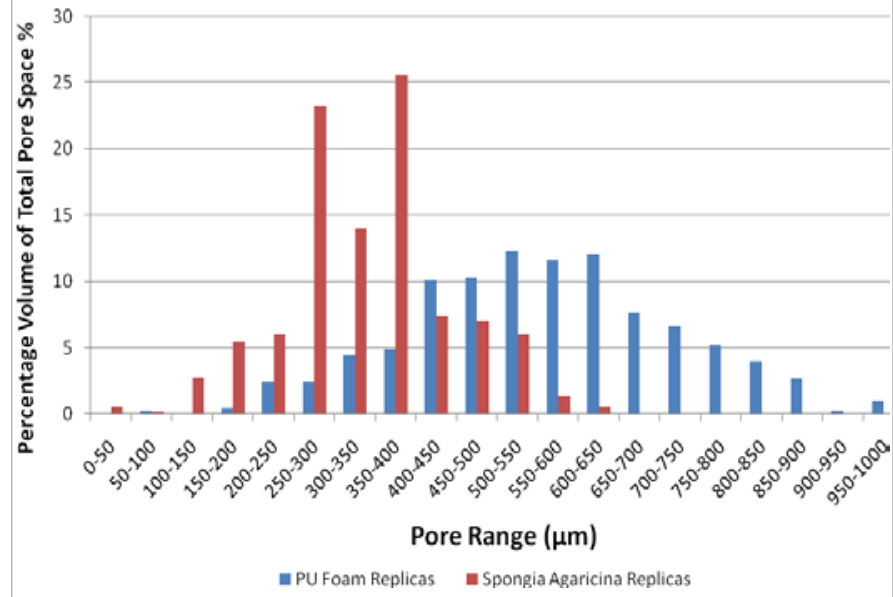

Figure 2: Percentage pore size distribution attained using Scanco MicroCT80 algorithms.

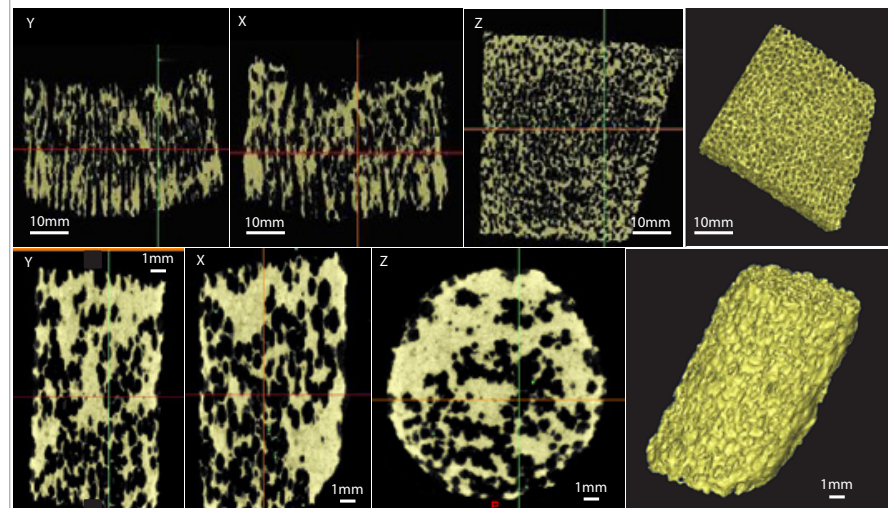

Figure 3: Tri-Axial view of PU foam replica scaffold (bottom line) and Spongia agaricina replica scaffold (top line) Internal architecture and 3-D reconstruction using Mimics V10.

\section{Analysis of cell growth}

After 1 day in culture, MG63s attached to Spongia agaricina replicas were viable but many retained a rounded morphology (Figure 8a). By 3 days however, the majority of cells exhibited a more fibroblast-like morphology (Figure $8 \mathrm{~b}$ ) and by 7 days, the majority of the scaffold has been colonised by cells. In comparison with MG63s, HDMECs showed improved adherence and increased proliferation by 1 day with typically elongated cells, indicating an affinity with the surface (Figure 8f). Adherence of HUVEC cells were comparable to MG63s.

On the PU foam replicas, many MG63s remained in a rounded morphology even at 5 days and 7 days by which time they had displayed an elongated morphology on the Spongia agaricina replicas (Figure 9ad). This suggested an inability to efficiently adhere to the scaffold. The viability of HUVEC cells on the PU foam replicas was comparatively poor with fewer cells identified at each time point. After a period of 7 days it was apparent that the majority of cells had died (Figure 9h). Similar results were seen with HDMECs and the cells failed to survive beyond $3 d$ (Figure $9 \mathrm{i}-\mathrm{j}$ ).

\section{Discussion}

The scaffolds produced using cellulose sponges and synthetic sponges (Table 1, chosen as representative of similar infiltration techniques) struggle to attain (or at the very least do not quantify) a pore size distribution suitable for complete integration into bone, as defined by Yang et al. [27]. In the current study, SEM/image analysis, micro-CT, and MIP provided evidence that both PU foam and Spongia agaricina replica scaffolds contain pores in the micro $(<20 \mu \mathrm{m})$, meso $(20-50 \mu \mathrm{m})$ and macro $(>50 \mu \mathrm{m})$ ranges necessary for complete integration $[27,44,45]$. While macropores play a well established role in osteoid ingrowth and rapid vascularisation [27], the presence of micro and mesoporosity is also essential, facilitating neovascularisation by providing increased surface area for protein adsorption and attachment points for osteoblasts $[27,44]$. This is reaffirmed by Woesz et al who state that the nutrition of the cells within any 3-D structure must be ensured for its viability, and that this is only possible via the flow of serum through both micro and macropores [45].

While there are discrepancies between the pore size distributions attained using MIP and micro-CT, (Table 2), the distribution pattern remains similar. These discrepancies may be due to the $50 \times 50 \times 50 \mu \mathrm{m} 3$ voxel resolution utilised for the latter. As such this resolution presents a limitation and may result in pores $<50 \mu \mathrm{m}$ being overlooked. MIP (Figure 4) reduces the discrepancy, providing pore size distribution data for pores between $1-1000 \mu \mathrm{m}$.

While literature suggests that the pore size distribution of the PU foam replicas developed will allow successful bone ingrowth it

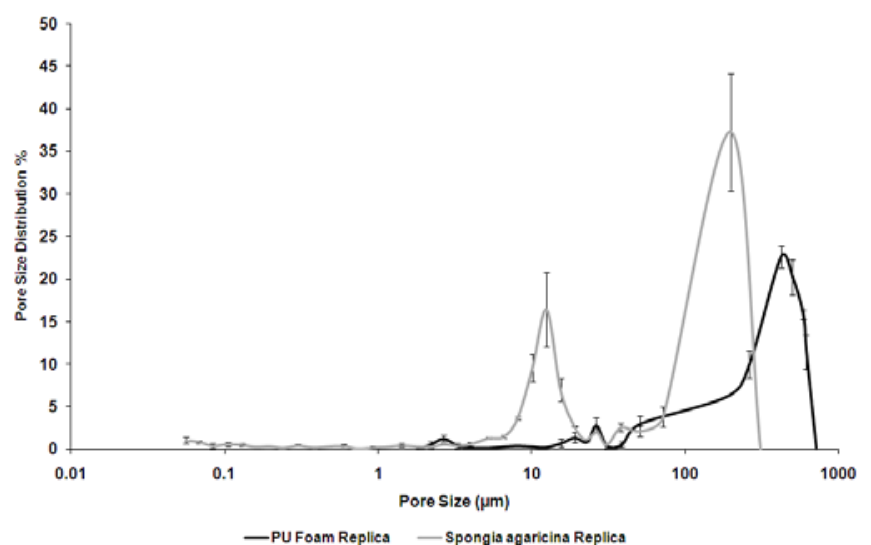

Figure 4: Pore size distribution determined via mercury porosimetry.

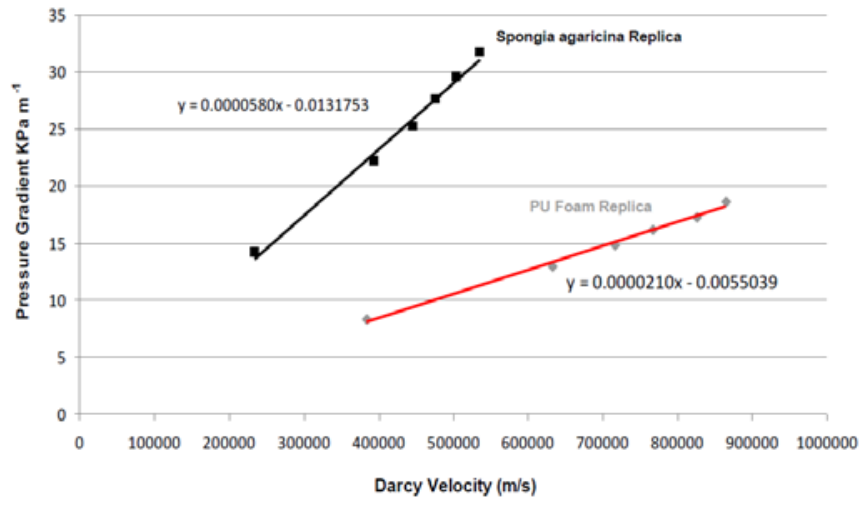

Figure 5: Mean pressure gradient Vs Darcy velocity 
Citation: Cunningham E, Dunne N, Clarke S, Choi SY, Walker G, et al. (2011) Comparative Characterisation of 3-D Hydroxyapatite Scaffolds Developed Via Replication of Synthetic Polymer Foams and Natural Marine Sponges. J Tissue Sci Eng S1:001. doi:10.4172/2157-7552. S1-001
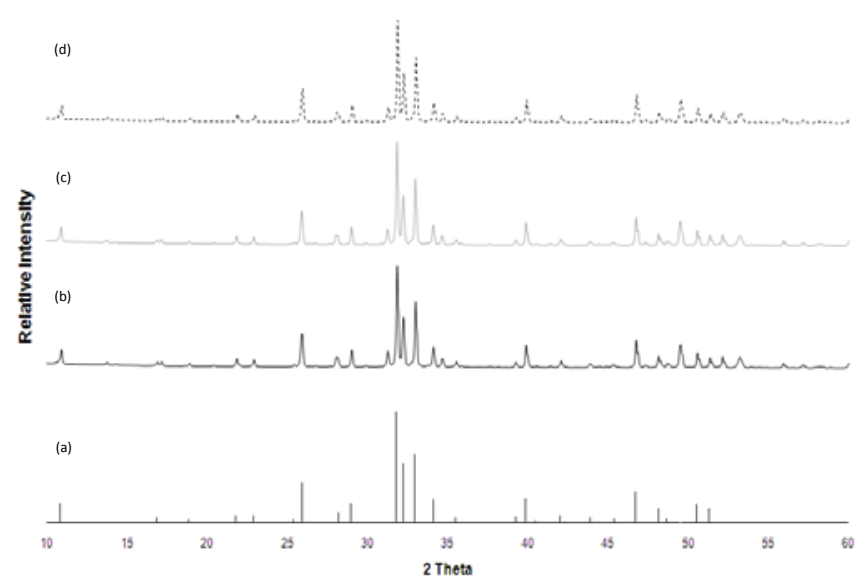

Figure 6: (a) HA stick pattern and XRD spectra of (b) As-received HA from Plasma Biota Ltd. (C) Replica PU foam and (d) Replica Spongia agaricina.

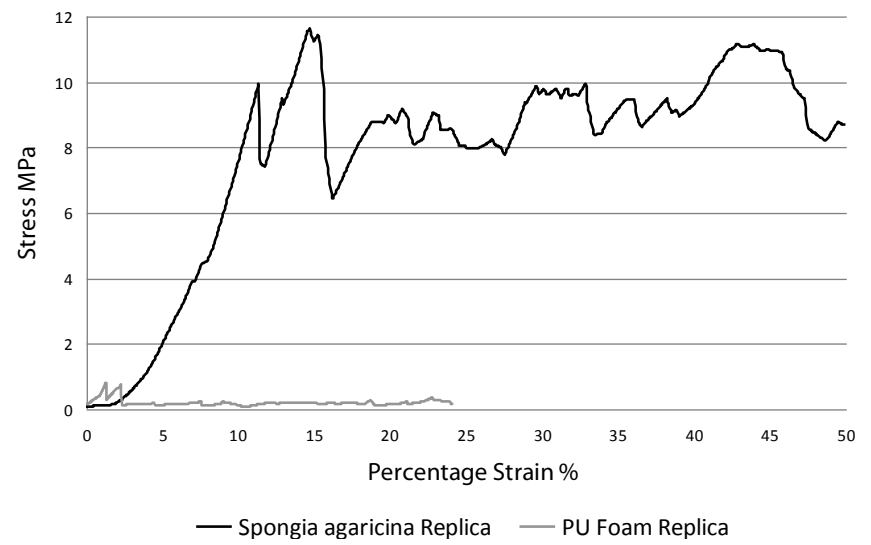

Figure 7: Typical stress vs. strain curve for Spongia agaricina replica and PU foam replica scaffolds.

speculates they will do so with limited success in comparison to the Spongia agaricina replicas. This is due to two main reasons; a) $41.8 \%$ of pores within the PU foam replicas fall within the 50-500 $\mu \mathrm{m}$ cited as necessary for bone ingrowth $[21,26,46,47]$ (with $>45 \%$ falling between $500-1000 \mu \mathrm{m}$ ) as opposed to $61.8 \%$ within the Spongia agaricina replicas and b) mirroring polymer foam replicas cited (Table 1), the PU foam replicas produced are deficient in pores between 1 and $50 \mu \mathrm{m}(<11 \%)$ which may severely limit neovascularisation, fibroblast ingrowth and bone ingrowth [27]. The literature suggests that Spongia agaricina replicas would be more successful at integrating with surrounding tissue [27].

Cited by Bohner et al as more influential to bone ingrowth than pore size [47], micro-CT quantitatively determined interconnectivity to be 99.99\% and $99.92 \%$ for the PU foam and Spongia agaricina replicas. In this instance it could be argued that these values are more meaningful having used a 50x50x50 $\mathrm{m} 3$ voxel resolution, given the consensus that a minimum pore opening of $50 \mu \mathrm{m}$ is required to facilitate cell and ion transport, and thus initiate osteogenesis [28,47-50]. While it may cause discrepancy in pore size distribution data, the determination of almost complete pore interconnectivity by micro-CT was validated using the scaffold permeability data. With $55-61 \%$ porosity and an average pore size of $349 \mu \mathrm{m}$ measured for the Spongia agaricina replicas, compared to $89 \%$ porosity and an average pore size of $577 \mu \mathrm{m}$ within $\mathrm{PU}$ foam replicas, increased permeability in the latter was expected.

The permeability values determined for both replicas calculated to be $\mathrm{k}=46.4 \mathrm{x} 10-10 \mathrm{~m} 2$ for $\mathrm{PU}$ foam and $\mathrm{k}=16.8 \mathrm{x} 10-10 \mathrm{~m} 2$ for Spongia agaricina are encouraging results. Both are in agreement with values reported by Nauman et al for vertebral body and proximal femur bone and by Grimm and Williams for calcaneus bone [51,52].

Interconnectivity between pores has also been demonstrated qualitatively using 3-D reconstruction of 2-D micro-CT images. While it provides only qualitative data it is a useful tool providing visual
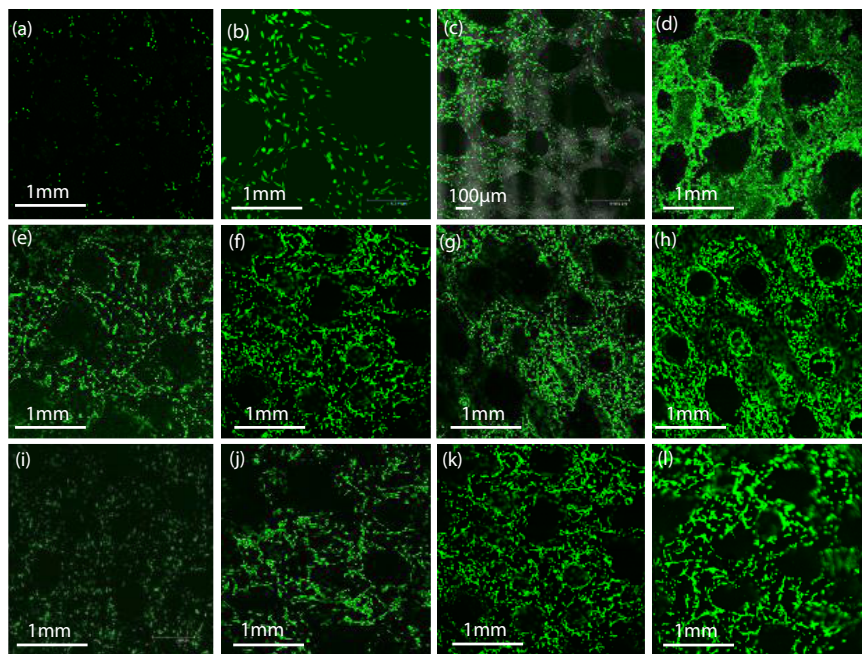

Figure 8 Calcein-AM stained MG63s seeded on Spongia agaricina replicas after (a) 1 Day (b) 3 Days (c) 5 Days (d) 7 Days. Calcein-AM stained HDMECs seeded on Spongia agaricina replicas after (e) 1 Day (f) 3 Days (g) 5 Days (h) 7 Days. Calcein-AM stained HUVECs seeded on Spongia agaricina replicas after (i) 1 Day (j) 3 Days (k) 5 Days (I) 7 Days. (All images are representative of cell coverage over the entire surface).
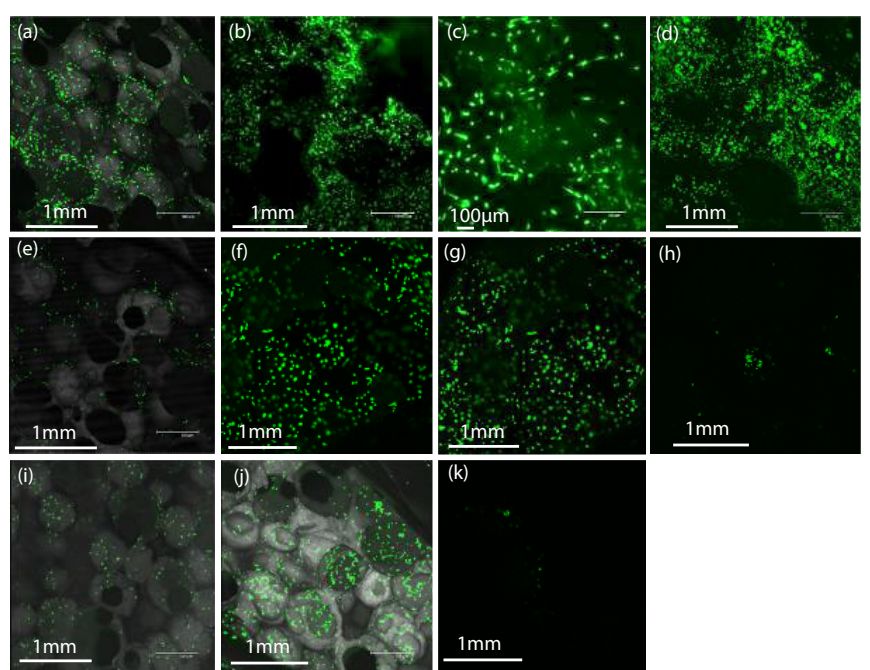

Figure 9: Calcein-AM stained MG63s seeded on PU Foam replicas after (a) 1 Day (b) 3 Days (c) 5 Days (d) 7 Days. Calcein-AM stained HUVECs seeded on PU Foam replicas after (e) 1 Day (f) 3 Days (g) 5 Days (h) 7 Days. Calcein-AM stained HDMECs seeded on PU Foam replicas after (i) 1 Days and (j) 3 Days (k) 5 days. (Images are representative of cell coverage over the entire surface). 
Citation: Cunningham E, Dunne N, Clarke S, Choi SY, Walker G, et al. (2011) Comparative Characterisation of 3-D Hydroxyapatite Scaffolds Developed Via Replication of Synthetic Polymer Foams and Natural Marine Sponges. J Tissue Sci Eng S1:001. doi:10.4172/2157-7552. S1-001

Page 7 of 9

\begin{tabular}{|c|c|c|c|c|c|c|}
\hline $\begin{array}{l}\text { Scaffold } \\
\text { Material }\end{array}$ & Preform & $\begin{array}{c}\text { Replica } \\
\text { Porosity } \\
(\%)\end{array}$ & $\begin{array}{c}\text { Replica Pore } \\
\text { Size Distribution } \\
(\mu \mathrm{m})\end{array}$ & $\begin{array}{l}\text { Compressive } \\
\text { Strength } \\
\text { (MPa) }\end{array}$ & Ref & SEM \\
\hline $\begin{array}{c}45 \mathrm{~S} 5 \\
\text { Bioglass }(\mathbb{8}\end{array}$ & $\begin{array}{l}\text { Polymer } \\
\text { Foam }\end{array}$ & $89-92$ & $510-720$ & $0.27-0.42$ & 13 & \\
\hline $\begin{array}{c}\text { Glass } \\
\text { Reinforced } \\
\text { HA } \\
\end{array}$ & $\begin{array}{l}\text { Polymer } \\
\text { Foam }\end{array}$ & $85-97.5$ & $420-560$ & $0.01-0.175$ & 12 & \\
\hline $\mathrm{HA}$ & $\begin{array}{l}\text { Polymer } \\
\text { Foam }\end{array}$ & - & $100-200$ & - & 20 & \\
\hline $\mathrm{HA}$ & $\begin{array}{l}\text { Polymer } \\
\text { Foam }\end{array}$ & $70-77$ & $200-400$ & $0.55-5$ & 19 & \\
\hline HA & $\begin{array}{l}\text { Polymer } \\
\text { Foam }\end{array}$ & $82-86$ & $500-700$ & $0.21-0.41$ & 16 & \\
\hline HA & $\begin{array}{l}\text { Polymer } \\
\text { Foam }\end{array}$ & 87 & $150-200$ & 0.16 & 15 & \\
\hline HA & $\begin{array}{l}\text { Polymer } \\
\text { Foam }\end{array}$ & - & $400-600$ & $1.3-10.5$ & 21 & \\
\hline HA & $\begin{array}{l}\text { Cellulose } \\
\text { Sponge }\end{array}$ & $65 \pm 5$ & $500-1000$ & N/A & 18 & \\
\hline $\begin{array}{c}\text { HA (20\% } \\
\text { Crystalline) }\end{array}$ & $\begin{array}{l}\text { Cellulose } \\
\text { Sponge }\end{array}$ & 56 & $50-2000$ & 16.1 & 14 & \\
\hline $\begin{array}{c}\text { HA (45\% } \\
\text { Crystalline) }\end{array}$ & $\begin{array}{l}\text { Cellulose } \\
\text { Sponge }\end{array}$ & 67 & $50-2000$ & 0.8 & 14 & \\
\hline $\begin{array}{c}\text { HA ( } 80 \% \\
\text { Crystalline) }\end{array}$ & $\begin{array}{l}\text { Cellulose } \\
\text { Sponge }\end{array}$ & 30 & $50-2000$ & 32.6 & 14 & \\
\hline $\mathrm{HA}$ & $\begin{array}{l}\text { Cellulose } \\
\text { Sponge }\end{array}$ & 45 & $100-200$ & $6 \pm 0.5$ & 17 & \\
\hline
\end{tabular}

Table 1: Scaffolds Developed via Replication of Porous Preforms.

evidence of pore interconnectivity and their respective tortuosity throughout each scaffold.

While Best et al have described the ability of several investigators to achieve bone ingrowth into scaffolds with porosities of $45-90 \%$, there are well established advantages to having levels at either end of the spectrum. High levels of porosity result in greater bone ingrowth while low levels increase mechanical stiffness and strength [53]. While both the Spongia agaricina and PU foam replicas exhibit porosity within the limits suggested by Best et al to have experienced bone ingrowth, its effect on the mechanical properties was evident. The $89 \%$ porous PU foam replica scaffolds possessed a compressive strength and compressive modulus of $2.46 \pm 1.43 \mathrm{MPa}$ and $0.099 \pm 0.014 \mathrm{GPa}$ respectively. With such relatively high porosity, however, these results compared favorably with the polymer foam replicas cited (Table 1). In contrast Spongia agaricina constructs developed have a compressive strength and compressive modulus of $8.4 \pm 0.83 \mathrm{MPa}$ and $0.164 \pm 0.016 \mathrm{GPa}$ respectively. These results are comparable to the replicated cellulose sponge scaffolds produced by Landi et al, who reported $45 \%$ porous scaffolds with a compressive strength of $6.0 \pm 0.5$ $\mathrm{MPa}$ [17]. Though replicated cellulose sponge scaffolds developed by Guicciardi et al exhibited a compressive strength of 16.1 MPa their porosity $(56 \%)$ and pore size distribution $(19 \mu \mathrm{m}-2 \mathrm{~mm})$ are inferior and interconnectivity was not reported.

Aside from the variation in porosity, the diminished mechanical properties of the PU foam replicas compared with Sponged agaricina replicas can be attributed to the disparity between average strut sizes [541 $\pm 214 \mu \mathrm{m}$ and $257 \pm 95 \mu \mathrm{m}$ for the PU foam and Spongia agaricina replica scaffolds respectively].
When engineering substitute bone, unlike the majority of engineering endeavours, the pursuit of mechanical strength in excess of what is required should be avoided. Wolff's law suggests that if a substitute is introduced with the mechanical capabilities exceeding those of the surrounding healthy bone, stress shielding may be induced, resulting in atrophy or tissue loss [54]. As such a scaffold should possess similar mechanical properties to the bone it has been designed to replace [31-33].

The average compressive strengths and compressive moduli of the natural polymer foam and marine sponge replicas, $2.46 \pm 1.43 \mathrm{MPa} / 0.099 \pm 0.014 \mathrm{GPa}$ and $8.4 \pm 0.83 \mathrm{MPa} / 0.16 \pm 0.016 \mathrm{GPa}$ respectively, fall within the range of properties quoted for healthy bone at various anatomical locations, Table 3 [31,32]. However, in the opinion of the author, the instability of PU foam replicas during routine handling, coupled with their relatively poor performance during testing limit their use to non load bearing applications. With regard to using Spongia agaricina replicas in load bearing applications, further testing under long term cyclic loading conditions is required.

In terms of cellular response, the primary aim of this investigation was to assess the viability of various primary cells and cell lines seeded onto the scaffolds. Endothelial cells play a major role, releasing proinflammatory factors and cell adhesion molecules and are the primary cells involved in the formation of new blood vessels [42]. Consequently, in addition to colonisation by osteoblasts, the adherence, proliferation and survival of endothelial cells on and within the implanted scaffolds are essential for successful integration into the body. It was evident that all three cell types investigated had a greater ability to adhere and proliferate on the surface of the Spongia agaricina replicas than on the PU foam replicas. This variation may be attributed to a number of factors;

a) Superior pore size distribution, in particular the presence of $1-50 \mu \mathrm{m}$ pores.

b) The presence of particulate HA on the surface of PU foam replicas; in the opinion of the author, the fine struts found in the PU foam replicas, evident in Figures 1(h), do not have sufficient stability to withstand handling without some degree of fracture. This instability has contributed greatly to the presence of HA particulate matter found on and within the constructs and has subsequently induced cellular phagocytosis and diminished the capacity of cellular material to adhere and proliferate across the surface. While a lack of visible cellular material on the surface of the PU Foam replicas

\begin{tabular}{|l|l|l|l|}
\hline HA Replica & $(\boldsymbol{\mu m})$ & Percentage 01 Total Pore Volume (\%) determined by \\
\hline & & micro-CT & MIP \\
\hline \multirow{3}{*}{ PU Foam } & $0-50$ & 0 & 10.7 \\
& $50-500$ & 35.5 & 41.8 \\
& $500+$ & 64.5 & 47.5 \\
\hline \multirow{4}{*}{ s. agaricina } & $0-50$ & 0.6 & 38.2 \\
& $50-500$ & 91.5 & 61.8 \\
& $500+$ & 7.9 & 0 \\
\hline
\end{tabular}

Table 2: Comparison of Pore Size Distribution Data Attained via $\mu-C T$ and MIP

\begin{tabular}{|l|l|l|l|l|l|}
\hline \multicolumn{2}{|l|}{$\begin{array}{l}\text { Young's Modulus } \\
\text { (GPa) }\end{array}$} & \multicolumn{2}{l|}{$\begin{array}{l}\text { Compressive } \\
\text { Strength (MPa) }\end{array}$} & \\
\hline Anatomical Location & Range & Average & Range & Average & Reference (s) \\
\cline { 2 - 6 } & $0.044-1.531$ & 0.389 & $0.56-22.9$ & 7.36 & {$[32]$} \\
\hline Femur & $0.001-0.110$ & 0.023 & $0.05-8$ & 1.55 & {$[32]$} \\
\hline Lumbar Spine & $0.061-1.174$ & 0.445 & $0.68-14.1$ & 5.33 & {$[31,32]$} \\
\hline Proximal Tibia & & 0.441 & & 6.8 & {$[31]$} \\
\hline Proximal Femoral & & & &
\end{tabular}

Table 3: Typical Mechanical Properties of Cancellous Bone. 
Citation: Cunningham E, Dunne N, Clarke S, Choi SY, Walker G, et al. (2011) Comparative Characterisation of 3-D Hydroxyapatite Scaffolds Developed Via Replication of Synthetic Polymer Foams and Natural Marine Sponges. J Tissue Sci Eng S1:001. doi:10.4172/2157-7552. S1-001

may signify migration into the pores the rounded morphology of the cellular material is indicative of cell death.

c) A combination of a larger surface area at the point of cell seeding and reduced permeability within the Spongia agaricina replicas has afforded the cellular material time to adhere increasing their potential for successful attachment and proliferation.

\section{Conclusions}

Both natural and synthetic preforms have been successfully used to manufacture HA based TE bone scaffolds. However, the natural marine sponge (Spongia agaricina) has presented itself as a potentially superior preform material for the production of such scaffolds in terms of the resulting pore structure and mechanical properties. The resultant scaffold demonstrated a normal pore distribution, with over $>90 \%$ within $1-500 \mu \mathrm{m}$ range. Moreover, $>99 \%$ of the pores were classified as interconnected and both permeability $(\mathrm{k}=16.8 \times 10$ $10 \mathrm{~m} 2$ ) and compressive properties measured were in agreement with values reported for healthy cancellous bone. Finally due to the pore architecture of the marine sponge replicas, they exhibited the ability to support adherence and proliferation of both primary endothelial cell types (HUVEC and HDMEC) and the osteoblast-like cell line MG63.

\section{References}

1. Parikh S (2002) Bone Graft Substitutes: Past, Present, Future. Postgrad Med 48: $142-148$

2. Rezwan K, Chen QZ, Blaker JJ, Boccaccini $A R(2006)$ Biodegradable and bioactive porous polymer/inorganic composite scaffolds for bone tissue engineering. Biomaterials27: 3413-3431.

3. Harris LD, Kim BS, Mooney DJ (1998) Open pore biodegradable matrices formed with gas foaming. J Biomed Mater Res 42: 396-402.

4. Gibson LJ (2005) Biomechanics of cellular solids. Journal of Biomechanics 38 377-99.

5. Oh SH, Kang SG, Kim ES, Cho SH, Lee JH (2003) Fabrication and characterization of hydrophilic poly(lactic-co-co-glycolic acid)/poly(vinyl alcohol) blend cell scaffolds by melt-molding particulate-leaching method. Biomaterials 24: 4011-4021.

6. Sultana N, Wang M (2008) Fabrication of HA/PHBV composite scaffolds through the emulsion freezing/freeze-drying process and characterization of the scaffolds. Journal of Materials Science. Materials in Medicine 19: 25552561.

7. Hu Y, Grainger DW, Winn SR, Hollinger JO (2002) Fabrication of poly(ahydroxy acid) foam scaffolds using multiple solvent systems. J Biomed Mater Res A 59: 563-572.

8. Zein I, Hutmacher DW, Tan KC, Teoh SH (2002) Fused deposition modeling of novel scaffold architectures for tissue engineering applications. Biomaterials 23: $1169-1185$.

9. Fierz FC, Beckmann F, Huser M, Irsen SH, Leukers B, Witte F, et al. (2008) The morphology of anisotropic 3D-printed hydroxyapatite scaffolds Biomaterials 29:3799-3806

10. Vozzi G, Flaim C, Ahluwalia A, Bhatia S (2003) Fabrication of PLGA scaffolds using soft lithography and microsyringe deposition. Biomaterials 24: 25332540 .

11. Kim TK, Yoon JJ, Lee DS, Park TG (2006) Gas foamed open porous biodegradable polymeric microspheres. Biomaterials 27:152-159.

12. Callcut S, Knowles JC (2002) Correlation between structure and compressive strength in a reticulated glass-reinforced hydroxyapatite foam. J Mater Sci Mater Med 13:485-489.

13. Chen QZ, Thompson ID, Boccaccini AR(2006) $45 S 5$ Bioglass derived glass ceramic scaffolds for bone tissue engineering. Biomaterials 27:2414-2425.

14. Guicciardi S, Galassi C, Landi E, Tampieri A (2001) Rheological characteristics of slurry controlling the microstructure and the compressive strength behavior of biomimetic hydroxyapatite. Journal of Material Research;16:163-170.
15. Kim HW, Knowles JC, Kim HE (2004) Hydroxyapatite/poly([var epsilon] caprolactone) composite coatings on hydroxyapatite porous bone scaffold for drug delivery. Biomaterials 25:1279-1287.

16. Kim HW, Knowles JC, Kim HE(2005) Hydroxyapatite porous scaffold engineered with biological polymer hybrid coating for antibiotic Vancomycin release. J Mater Sci Mater Med 16:189-195.

17. Landi E, Celotti G, Logroscino G, Tampieri A (2003) Carbonated hydroxyapatite as bone substitute. Journal of the European Ceramic Society 23: 2931-2937.

18. Mastrogiacomo M, Scaglione S, Martinetti R, Dolcini L, Beltrame F, et al. Role of scaffold internal structure on in vivo bone formation in macroporous calcium phosphate bioceramics. Biomaterials 27:3230-3237.

19. Ramay HR, Zhang M (2003) Preparation of porous hydroxyapatite scaffolds by combination of the gel-casting and polymer sponge methods. Biomaterials 24: 3293-3302

20. Saiz E, Gremillard L, Menendez G, Miranda P, Gryn K, Tomsia AP. Preparation of porous hydroxyapatite scaffolds. Materials Science and Engineering 27:546550

21. Sopyan I, Mel M, Ramesh S, Khalid KA (2007) Porous hydroxyapatite fo artificial bone applications. Science and Technology of Advanced Materials 8:116-123.

22. Tancred DC, McCormack BAO, Carr AJ (1998) A synthetic bone implant macroscopically identical to cancellous bone. Biomaterials 19: 2303-2311.

23. Vats A, Tolley NS, Polak JM, Gough JE (2003) Scaffolds and biomaterials for tissue engineering: a review of clinical applications. Clin Otolaryngol 28: 165172

24. Best SM, Porter AE, Thian ES, Huang J (2008) Bioceramics: Past, present and for the future. Journal of the European Ceramic Society 28:1319-1327.

25. Engin NO, Tas AC(1999) Manufacture of Macroporous Calcium Hydroxyapatite Bioceramics. Journal of the European Ceramic Society 19:2569-2572.

26. Giannoudis PV, Dinopoulos H, Tsiridis E (2005) Bone substitutes: An update. Injury 36: S20-S7.

27. Yang S, Leong KF, Du Z, Chua CK. (2001) The Design of Scaffolds for Use in Tissue Engineering. Part 1. Traditional Factors. Tissue Engineering 7: 679-689.

28. Woodard JR, Hilldore AJ, Lan SK, Park CJ, Morgan AW, et al.(2007) The mechanical properties and osteoconductivity of hydroxyapatite bone scaffolds with multi-scale porosity. Biomaterials $28: 45-54$

29. Bignon A, Chouteau J, Chevalier J, Fantozzi G, Carret JP, et al.( 2003) Effect of Micro- and Macroporosity of Bone Substitutes on their Mechanical Properties and Cellular Response. Materials in Medicine 14: 1089-1097.

30. Cyster LA, Grant DM, Howdle SM, Rose FRAJ, Irvine DJ, et al. (2005) The influence of dispersant concentration on the pore morphology of hydroxyapatite ceramics for bone tissue engineering. Biomaterials 26: 697-702.

31. Karageo rgiou V, Kaplan D (2005) Porosity of 3D biomaterial scaffolds and osteogenesis. Biomaterials 26: 5474-91.

32. Keaveny TM. Cancellous B. In: Black J, Hastings G, editors. Handbook of Biomaterial Properties. First ed: Chapman and Hall 17.

33. Babis GC, Soucacos PN (2005) Bone scaffolds: The role of mechanical stability and instrumentation. Injury 36: S38-S44.

34. Williams DF(1987) Definitions in biomaterials. Amsterdam: Elsevier

35. Unger R, Peters K, Huang Q, Funk A, paul D, et al. (2005) Vascularization and gene regulation of human endothelial cells growing on porous polyethersulfone (PES) hollow fiber membranes. Biomaterials 26: 3461-3469.

36. Cunningham E, Dunne N, Walker G, Buchanan F(2009) High-solid-conten hydroxyapatite slurry for the production of bone substitute scaffolds. Proceedings of the Institution of Mechanical Engineers, Part $\mathrm{H}$ : Journal of Engineering in Medicine 223: 727-737.

37. Cunningham E, Dunne N, Walker G, Maggs C, Wilcox R, et al. (2010) Buchanan F. Hydroxyapatite Bone Substitutes Developed via Replication of Natural Marine Sponges. Journal of Materials Science: Materials in Medicine 21: 2255-2261.

38. Cunningham E (2008.) Development of Bone Substitutes Based on Biomimetic Structures. Belfast: Queen's University 
Citation: Cunningham E, Dunne N, Clarke S, Choi SY, Walker G, et al. (2011) Comparative Characterisation of 3-D Hydroxyapatite Scaffolds Developed Via Replication of Synthetic Polymer Foams and Natural Marine Sponges. J Tissue Sci Eng S1:001. doi:10.4172/2157-7552. S1-001

39. Marshall AJ, Ratner BD (2005) Quantitative Characterization of SphereTemplated Porous Biomaterials. AIChE Journal 51: 1221-1232.

40. Zhang J, Tanaka H, Ye F, Jiang D, Iwasa M (2007) Colloidal processing and sintering of hydroxyapatite. Materials Chemistry and Physics 101: 69-76.

41. Santos MI, Fuchs S, Gomes ME, Unger RE, Reis RL, et al. (2007) Response of micro- and macrovascular endothelial cells to starch-based fiber meshes for bone tissue engineering. Biomaterials 28: 240-248

42. Unger R, Sartoris A, Peters K, Motta A, Migliaresi C, et al.( 2007) Tissuelike self-assembly in cocultures of endothelial cells and osteoblasts and the formation of microcapillary-like structures on three-dimensional porous biomaterials. Biomaterials 28: 3965-3976.

43. Pronzato R, Manconi R (2008) Mediterranean commercial sponges: over 5000 years of natural history and cultural heritage. Marine Ecology 29: 144-166.

44. Hing KA, Wilson LF, Buckland T(2007) Comparative performance of three ceramic bone graft substitutes. The Spine Journal 7: 475-490.

45. Woesz A, Rumpler M, Stampfl J, Varga F, Fratzl-Zelman N, et al.(2005)Towards bone replacement materials from calcium phosphates via rapid prototyping and ceramic gelcasting. Materials Science and Engineering: C 25: 181-186.

46. Bohner M, Baumgart F (2004) Theoretical model to determine the effects of geometrical factors on the resorption of calcium phosphate bone substitutes. Biomaterials 25: 3569-3582.

47. von Doernberg MC, von Rechenberg B, Bohner M, Grünenfelder S, van Lenthe
$\mathrm{GH}$, et al. In vivo behavior of calcium phosphate scaffolds with four different pore sizes. Biomaterials 27: 5186-198.

48. Chang BS, Lee CK, Hong KS, Youn HJ, Ryu HS, et al. Osteoconduction at porous hydroxyapatite with various pore configurations. Biomaterials 21: 12911298.

49. Gauthier O, Bouler JM, Aguado E, Pilet P, Daculsi G. Macroporous biphasic calcium phosphate ceramics: influence of macropore diameter and macroporosity percentage on bone ingrowth. Biomaterials 19: 133-139.

50. Le Huec JC, Schaeverbeke T, Clement D, Faber J, Le Rebeller A (1995) Influence of porosity on the mechanical resistance of hydroxyapatite ceramics under compressive stress. Biomaterials 16: 113-118.

51. Grimm MJ, Williams JL (1997) Measurements of permeability in human calcaneal trabecular bone. Journal of Biomechanics 30: 743-745.

52. Nauman EA, Fong KE, Keaveny TM (1999) Dependence of Intertrabecular Permeability on Flow Direction and Anatomic Site. Annals of Biomedical Engineering 27: 517-524

53. Byrne DP, Lacroix D, Planell JA, Kelly DJ, Prendergast PJ (2007) Simulation of tissue differentiation in a scaffold as a function of porosity, Young's modulus and dissolution rate: Application of mechanobiological models in tissue engineering. Biomaterials 28: 5544-554

54. Black J. Stress Shielding. Biological Performance of Materials: Fundamentals of Biocompatibility. Fourth Edition ed: CRC Press. p. 191 